\title{
The Research of Navigational Safety Control in Taiwan Strait
}

\author{
Shaoqi Jiang ${ }^{1, a}$, Wanzheng $\mathrm{Ai}^{2, \mathrm{~b}}$ \\ ${ }^{1}$ Marine College of Zhejiang Ocean University, Zhoushan 316000, P. R. China \\ ${ }^{2}$ Marine College of Zhejiang Ocean University, Zhoushan 316000, P. R. China \\ aEmail: 1320180450 @qq.com, ㄹEmail:aiwanzheng@126.com
}

\begin{abstract}
Keywords: navigational environment, vessel maneuvering, collision avoidance, the safety of navigation
\end{abstract}

\begin{abstract}
With the rapid development of economy, our country's marine transportation passageways get more crowded. Especially in the region of Taiwan Strait, crude oil import in East Asian districts as well as the transportation between lines in the North and South makes traffic busier than ever before. Besides, since the permission of vessels correspondence between Taiwan and China accompanied by greatly increasing encounter probability of vessels, the navigation safety in Taiwan Strait appears extremely essential. This article aims to provide security guidance covering risk aversion for vessels sailing in the Taiwan Strait by integrating information such as stream, physiognomy and meteorology of straits
\end{abstract}

\section{The analysis of navigational environment in straits}

Taiwan Strait is located in the middle of China's east coast and the west coast of Taiwan Island in alignment from northeast to southwest on the whole. Fujian Province and Taiwan Island, on the two sides of the strait, are all characterized with land topography with mountains of southwest to northeast while the water area of straits are shaped like a horn with the south wide and the north narrow. Therefore, the airflow is affected by this kind of landform which causes the funneling ${ }^{[1]}$ to increase the strength of the wind, stream and billow (Funneling, also called canyon effect or neck beam effect, refers to the influence on airflow by canyon terrain. When the airflow from the open area flows into the terrain of the canyon, due to the fact that the air cannot be piled up, the movement through the canyon is accelerated, so the wind speeds up. On the contrary, when the air gets out of the canyon, air velocity slows down ${ }^{[2]}$ ). The strait, near the Tropic of Cancer, is subject to subtropical monsoon climate. In winter, there's a strong wind from the north or northeast while in summer it turns from the south or southwest. Moreover, the strait area belongs to the zone with high incidence of typhoon in summer which leads to apparent changes on airflow field and the wave. In addition, the north of the Strait is one of the areas of fog in China's main off shores mainly in the form of the advection fog. In the period from January to May is the season full of fog in a year with the thickest fog in March and April. It is unfavorable for the safety of navigation for the fog does exert a great impact on visibility with the data that the average annual fog days are up to 37.

Two large-scale fisheries are settled in the center and south of Fujian because of abundant fishery resources there. It is no doubt that the number of fishing boats is quite considerable. Combined with the sustaining increase on the number of vessels between the north-south and cross-strait direct transportation, business as well as fishing line vessels are crossed completely. It's hardly to evade especially when the vessel gets into fishing area. Furthermore, merchant officers' increasing reliance on technology of radar, AIS, VHF such navigational equipment, together with the ignorance of proper look-out of the vessel and collision avoidance, the risk of navigation in intensive fishing zone is tightened. What's more, Fujian and Taiwan haven't reached a full sharing of information resulting in the AIS data missing and inability to realize collision avoidance accurately. What's worse, the humble and incomplete navigation AIDS couldn't adapt to the huge traffic flow. All the facts prevent the realization of safe navigation for the vessel. 


\section{Countermeasures for safe navigation for the vessel}

This part is designed to reduce the frequency of safety accidents and improve the skills of the officers via the guidance of rational analysis for the vessel associated with the special navigation environment in the Taiwan Strait.

The vessel maneuvering in the wind

Under the condition that the Taiwan Strait on the whole is in alignment from northeast to southwest with a strong wind from the north or northeast in winter while from the south or southwest in summer, it can be inferred that the vessel is mainly faced with the wind to forward the beam in the process of sailing to the north in winter. In order to keep heading, the vessel sailing in the wind must overcome the pressure of the wind Fa, so it's forced to maintain a certain amount of leeway Angle, namely the Drift Angle. The existence of the Drift Angle demonstrates that the vessel is in a loxodromic state bringing about hydrodynamic force (Fh). As the pressure of wind and hydrodynamic force don not function in the middle of the vessel, in virtue of the formation of torques by the pressure of wind and hydrodynamic force, the vessel moves and the Course Angle changes. The stress situation of the wind to forward the beam is shown in figure 1 .

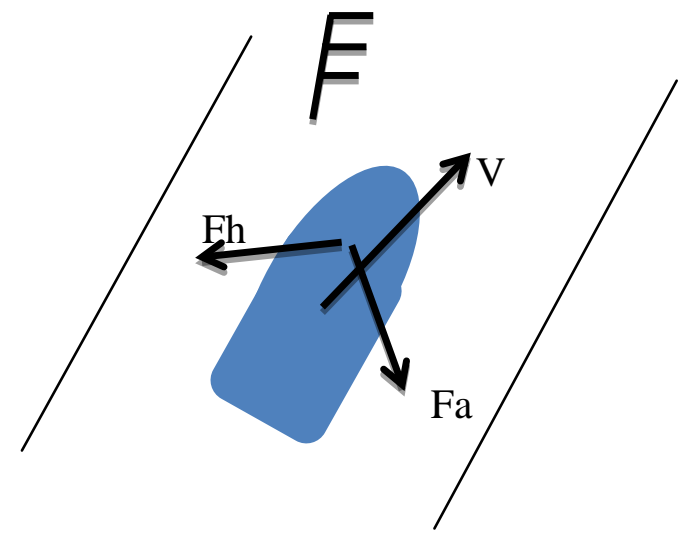

Figure 1 the stress situation of the wind to forward the beam

Direction of rotation of the vessel, namely the direction of torque driven by net force depends on the relative position between the center of hydrodynamic force and the pressure of wind. If the vessel is at high speed, the center of hydrodynamic force moves towards, then the torque of wind pressure is smaller than the torque of hydrodynamic. As a result, the vessel bow deflects towards windward side. In this point, the officer should balance the rudder appropriately towards leeward side. If the center of lateral area of vessel above he water is close to the bow, the center of hydrodynamic force moves backwards, then the torqua of wind pressure is greater than the torque of hydrodynamic. As a result, the vessel bow deflects towards leeward side. In this point, the officer should balance the rudder appropriately towards windward side. Conference with the wind to abaft the beam on the stern of vessel, sailing to the south in winter, giving rise to the accordance with torques of the wind pressure and hydrodynamic force, the bow deflect towards leeward side. It can be noticed that the impact of wind to abaft the beam for the sailing vessel is greater than that of the wind to forward the beam. Hence, more cautions are need when the vessel sails to the south. The vessels sailing to the south or north in summer are applied to the same principle which can be perceived as a reference. Due to the impact on different vessels on the voyage by wind current varies, relevant IMO data can be taken into consideration when officers maneuver the vessel in person. A vessel with blowing wind to the beam, for example, if its relative speed of vessel is 20 $\mathrm{m} / \mathrm{s}$ (8 magnitude of wind power), the speed of vessel is $10 \mathrm{Kn}$, Va (the speed of wind) /V (the speed of vessel) is around 4, then the course can be maintained as before through steering the rudder Angle at $15^{0}$ no matter in conditions of full loading or ballasting. On the other case, if the speed of vessel is at $5 \mathrm{Kn}, \mathrm{Va} / \mathrm{V}$ is approximately 8 , and then the course yet can be maintained through steering the rudder Angle at $35^{\circ}$ in full loading while it cannot be achieved ballasting ${ }^{[3]}$. At this 
point, the speed of vessel should be accelerated to improve the effectiveness of steering for safe navigation, otherwise collision or grounding is likely to occur.

The area of Strait is easily affected by the typhoon for it lands directly with high possibility. When the vessel is sailing into the typhoon region accidentally, the vessel's position in the typhoon should be judged first according to the early warning report of typhoon by meteorological department. If relevant information is unavailable, the officer also can make continuous observation to the direction of true wind at certain intervals when the vessel is heaving to. It shows that vessel is in the right semi-circle of cyclone if the wind changes clockwise while it is in the opposite position if the wind changes anticlockwise. It can be divided into left- and right- semicircle according to the typhoon moving direction. The left-semicircle is relatively safe, also called navigable semicircle, then the right-semicircle is named dangerous semicircle ${ }^{[4]}$. Because the direction of wind in right-semicircle and the cyclone is nearly close on the whole, the speed of wind is accelerated. That's why the front part of semi-circle is called Dangerous Quadrant. When the vessel is near this area, it is easily blown into the center of cyclone and out of control.

If the vessel has been into the dangerous semicircle, the starboard of bow should be steered at full speed against the wind to leave holding the wind Angle at $10^{\circ}$ to $30^{\circ}$ until leaving the dangerous zone absolutely. If the vessel is in the navigable semicircle, the starboard of stern should be steered downwind to leave holding the wind Angle at $30^{\circ}$ to $40^{\circ}$. In the event of fierce winds and waves, the vessel must be heaved to so as to escape the danger with the help of the movement of cyclone. However, the better choice is to stay in the Shelter Anchorage until the typhoon passes by to lower the risk of navigation.

The Taiwan Strait is swarmed with various fishing vessels. It is a universal phenomenon that more and more officers are personnel with low skill levels who work in the land intially. In addition, owing to unfamiliarity with "International Regulations for Preventing Collisions at Sea, the proper lights and shapes cannot be displayed by fishing officers which interferes with merchant vessels' judgment about the movement and operation tendency of fishing vessels. As a result, timely and effective measures to avoid collision cannot be taken.

Then we come to the guidance on collision avoidance between merchant vessels and fishing vessels. Here is a part of the "Rule 18"

Expect where Rules 9, 10 and 13 otherwise require:

(a) A power-driven vessel underway shall keep out of the way of:

(i) a vessel not under command

(ii) a vessel restricted in her ability to manoeuvre

(iii) a vessel engaged in fishing

(iv) a sailing vessel

It's universally acknowledged that the merchant vessels in the process of navigation should bear the responsibility of giving way to the vessels engaged in fishing ${ }^{[5]}$. Except recognizing the lights and shapes of fishing vessels, merchant vessels should proactively detect fishing vessels averting the severe reliance on radar and other navigational equipment blindly. When it comes to the routes design, safety of avoiding the vessel should be given full consideration. Supposing that the merchant vessel steams into fishing area, the surrounded environment and the distribution of vessels should be carefully observed. Meanwhile, it shold avoid getting into compact district of fishing vessels to get away from there as far as possible.

In the course of sailing in fishing area, look-out should be enhanced by merchant vessels at a safe speed. If there's any evidence of collision risk, officer should keep clear of the fishing vessel as early as possible and pay more attention to the trend of the fishing vessels and stretching direction of fishing gears. The fishing gears should be avoided touching as well. If the merchant vessel is trapped into fishing nets during the voyage, the officer should immediately stop engine to drift in case of the propeller will be entangled causing unnecessary loss. Provided that merchant vessel encounters the motor fishing vessel which isn't engaged in fishing, it should be noticed that the 
officer of the fishing vessel may has no idea about the fact that the fishing vessel belongs to common motor vessel without the right to take-on. Consequently, collision avoidance should be implemented proactively if necessary.

\section{Conclusion}

Nowadays, with the increasingly crowded traffic day by day in Taiwan Strait in the form of overlapped vessel ping lines anywhere which renders collision avoidance more difficult, marine accidents occur from time to time. The safety of life at sea and the marine environment are tremendously threaded. There is a strong appeal that facing such severe vessel ping situation, all the officers should be welly trained to improve individual skills, all the navigational marks should be consummated and the management of traffic at sea shoud be regulated to establish a safe and efficent navigation environment, to ensure the safety of officers.

\section{References}

[1] The Taiwan Strait - BoYu Wu climate characteristics, the state oceanic administration analysis and application of the third Marine research institute in December 1982

[2] Funnelling -Ming Yang, geographical mathematics in 18, 2014

[3] Vessel maneuvering -ZhiGuang Hong, Dalian maritime university press in 2008

[4] Navigational meteorology and oceanography-YongNing Zhang, China communication press in 2012

[5] Ship collision avoidance and watch keeping-ZhaoLin Wu, Dalian maritime university press in 4, 2014 